\title{
, \\ Standardizing Performance Metrics for Building-Level Electrical Distribution Systems
}

\author{
Moazzam Nazir ${ }^{1, *(\mathbb{D})}$, Omkar Ghatpande ${ }^{1, *(\mathbb{D}}$, Willy Bernal Heredia ${ }^{1, *(\mathbb{D}}$, Cameron Wierzbanowski ${ }^{1}$, \\ Daniel Gerber ${ }^{2}$ and Avijit Saha ${ }^{1}$ \\ 1 National Renewable Energy Laboratory, Golden, CO 80401, USA; cwierzbo@gmail.com (C.W.); \\ avijit.saha@nrel.gov (A.S.) \\ 2 Lawrence Berkeley National Laboratory, Berkeley, CA 94720, USA; dgerber@lbl.gov \\ * Correspondence: moazzam.nazir@nrel.gov (M.N.); omkar.ghatpande@nrel.gov (O.G.); \\ Willy.BernalHeredia@nrel.gov (W.B.H.)
}

check for updates

Citation: Nazir, M.; Ghatpande, O.A.; Bernal Heredia, W.G.;

Wierzbanowski, C.; Gerber, D.; Saha, A. Standardizing Performance Metrics for Building-Level Electrical Distribution Systems. Energies 2022, 15, 136. https://doi.org/10.3390/ en15010136

Academic Editor: Monica Siroux

Received: 20 November 2021 Accepted: 20 December 2021 Published: 25 December 2021

Publisher's Note: MDPI stays neutral with regard to jurisdictional claims in published maps and institutional affiliations.

Copyright: (C) 2021 by the authors Licensee MDPI, Basel, Switzerland. This article is an open access article distributed under the terms and conditions of the Creative Commons Attribution (CC BY) license (https:// creativecommons.org/licenses/by/ $4.0 /)$.

\begin{abstract}
Building-level electrical distribution systems comprise a myriad of current-carrying equipment, conversion devices, and protection devices that deliver power from the utility or local distributed energy resources to end-use building loads. Electric power has traditionally been generated, transmitted, and distributed in alternating current (AC). However, the last decade has seen a significant increase in the integration of native direct current (DC) equipment that has elevated the importance of DC distribution systems. Numerous studies have comparatively examined the performance of various electrical distribution systems in buildings but have failed to achieve uniform conclusions, primarily because of a lack of consistent and analogous performance evaluation methods. This paper aims to fill this gap by providing a standard set of metrics and measurement boundaries to consistently evaluate the performance of AC, DC, or hybrid AC/DC electrical distribution systems. The efficacy of the proposed approach is evaluated on a representative medium-sized commercial office building model with AC distribution and an equivalent hybrid AC/DC and DC distribution model, wherein the AC distribution model is concluded to be the most efficient. The simulation results show variation in computed metrics with different selected boundaries that verify the effectiveness of the proposed approach in ensuring consistent computation of the performance of building-level electrical distribution systems. This paper provides an initial set of guidelines for building energy system stakeholders to adopt appropriate solutions, thus leading to more efficient energy systems.
\end{abstract}

Keywords: AC and DC electrical power distribution; buildings; energy efficiency; metrics; standardization

\section{Introduction}

\subsection{Background}

The negative repercussions of increasing carbon levels in the atmosphere have prompted an urgent need to curb carbon emissions by adopting energy-efficient technologies and green energy resources. Countries around the globe have signed numerous agreements and commitments focused on net-zero emissions. Almost $80 \%$ of global greenhouse gas emissions are attributed to cities, with half of that amount coming from buildings [1]. Accordingly, robust measures are being adopted to decrease building emissions and energy utilization while increasing on-site generation and efficiency [2].

Since the 1880s, alternating current (AC) has been preferred over direct current (DC) for electrical power transmission and distribution. At the time, the transformer was the only viable means of voltage conversion, which allowed for reduced power loss in longdistance transmission $[3,4]$. The basic concepts in electrical distribution have remained unchanged since the 19th century. However, due to significant advancements in power electronic converters, which enabled efficient voltage transformation, allowing DC systems to become comparable to transformers in AC systems, DC has once again emerged as a compelling option for transmission and distribution purposes. In buildings, DC systems 
have inherent benefits over their AC counterparts. DC systems have fewer conversion stages, which can significantly increase energy efficiency; a single conversion stage can exhibit losses ranging from $5 \%$ to $14 \%$ [5]. They also pose less danger than AC at similar voltage levels. DC systems do not suffer from synchronization challenges, and they can provide better power quality and achieve higher reliability. They can easily incorporate static storage and facilitate the integration of distributed energy resources (DERs) (mostly DC-native) $[5,6]$. In addition, once economies of scale are reached, DC will reduce a system's upfront cost due to reduced installation costs and comparatively simple power electronics with fewer components [7]. Finally, DC systems do not exhibit skin effect and reactive power, leading to higher efficiency. As a result of these advantages and the increased adoption of miscellaneous electric loads in buildings that operate internally on DC, building-level DC distribution systems have emerged as a promising alternative to AC distribution.

\subsection{Motivation}

Despite the many cited advantages of DC, AC distribution systems are still dominant in buildings. Among the reasons for this trend, which include technological challenges and the widespread existence of AC equipment, is the lack of standards and metrics for measuring and comparing distribution systems, especially at the building level [8]. Past research efforts measured electrical distribution performance metrics in different ways, with variations both in system and component definitions and in measurement points/nodes. Such discrepancies have led to large variations and disagreement in the results of AC and DC electrical distribution system performance studies. For example, refs. [4,5,9-14] all report different increases in efficiency $(2.3-15 \%)$ when using DC systems in place of AC systems, whereas $[15,16]$ conclude that AC distribution systems are more efficient. Interestingly, ref. [17] reports that comparing a 100\% AC system to a $100 \%$ DC system is unrealistic and proposes hybrid AC/DC systems as a more logical and possibly more efficient solution to energy efficiency challenges.

Apart from these studies, few past works have conducted a detailed analysis of all the losses in building energy systems. Multiple research groups are working on DC distribution systems, including the European Telecommunications Standards Institute, the EMerge Alliance, and the International Electrotechnical Commission. However, their efforts are focused on the voltage level of distribution systems, the operating voltage range, and the grounding structure [9]. Previous works suggest a variety of performance metrics (efficiency, power quality, reliability, etc.) associated with building energy systems [18-20] but have not described an appropriate, uniformly applicable measurement strategy for all building types. This underscores the need for standardized performance metrics for building-level electrical distribution systems. The use of a standardized set of metrics will be an essential tool for comparing all future advancements in components and distribution system topologies.

\subsection{Contribution}

The development of performance metrics for a building's electrical apparatus is an intricate challenge due to equipment diversity (e.g., transformers, converters, wiring, and breakers). Assumptions and system boundary allocations can significantly alter the associated metrics [10]. This paper proposes a methodology to consistently measure a variety of performance metrics associated with building-level electrical distribution systems. The proposed strategy consists of two steps:

1. Boundary allocation

2. Metrics estimation

The boundary allocation involves drawing hypothetical boundaries along different building regions according to purpose or characteristic (e.g., DC-only). Later, these boundaries are utilized to compute a variety of performance metrics proposed in this work. This helps to reliably compare distribution systems across buildings and configurations. 
Accordingly, this paper allows for the measurement, comparison, and improvement of any building-level electrical distribution system. The paper also evaluates the proposed method by applying the accompanying metrics to a case study of an AC building system and a hybrid AC/DC building system.

The rest of this paper is organized as follows: Section 2 explains the proposed strategy, which involves the two major steps of distribution system boundary allocation and metrics definition and measurement. Section 3 presents the case study of a commercial reference building model (CRBM), which is used to evaluate the proposed strategy. Section 4 presents the simulation results, and Section 5 is dedicated to discussion. Finally, Section 6 concludes with possible future directions.

\section{Proposed Approach}

A uniform methodology is essential for the successful comparison of electrical distribution system topologies across different building types. This methodology should be able to be reliably adopted by the building community. Our work achieves this objective by first selecting an appropriate evaluation boundary from a set of electrical distribution system boundaries, which are defined in the following section. Next, the most critical performance metrics are computed from measurements or models along the periphery of the selected boundary. This method is uniformly applicable to a broad range of AC, DC, and hybrid systems and can thus be used to evaluate existing and future building electrical distribution system designs.

\subsection{Typical Building Electrical Distribution System}

A typical building electrical distribution system comprises electrical sources (grid, diesel generator (DG), photovoltaics (PV), and battery energy storage system (BESS)) and end-use loads (lighting, motors, electronics, and heating, ventilating, and air conditioning). The intermediate equipment between the sources and loads, which is responsible for the safe and reliable delivery of power, consists of wires, buses, electrical panels, and protection and conversion equipment.

\subsection{Boundary Allocation}

Before defining the performance metrics associated with building-level electrical distribution systems, consistent boundary definitions are required. This is essential because the computed metrics are highly dependent on the selected boundary, with results varying considerably along different boundaries. This step allocates different boundaries within a building, which are divided into five categories: whole-building boundary, building electrical distribution system boundary, building electrical distribution system boundary plus primary conversion stages, DC-only distribution boundary, and end-use load boundary. Figure 1 depicts these boundaries.

- The whole-building boundary comprises the entire building electrical distribution system, starting from the point of common coupling. On-site energy sources (PV, BESS, DG, etc.) are also considered part of the whole-building boundary, as they are not metered by the electric utility.

- The building electrical distribution system boundary includes the intermediate equipment between the point of common coupling and the end-use loads. In the case of a building that has interconnected on-site energy sources, this boundary also includes the converters associated with them.

- $\quad$ The building electrical distribution system boundary plus primary conversion stages includes all the equipment encompassed by the previous boundary plus the internal conversion equipment associated with the end-use loads.

- The DC-only distribution boundary encompasses all the DC distribution of the overall system.

- $\quad$ The end-use load boundary includes the loads and their associated conversion equipment. 


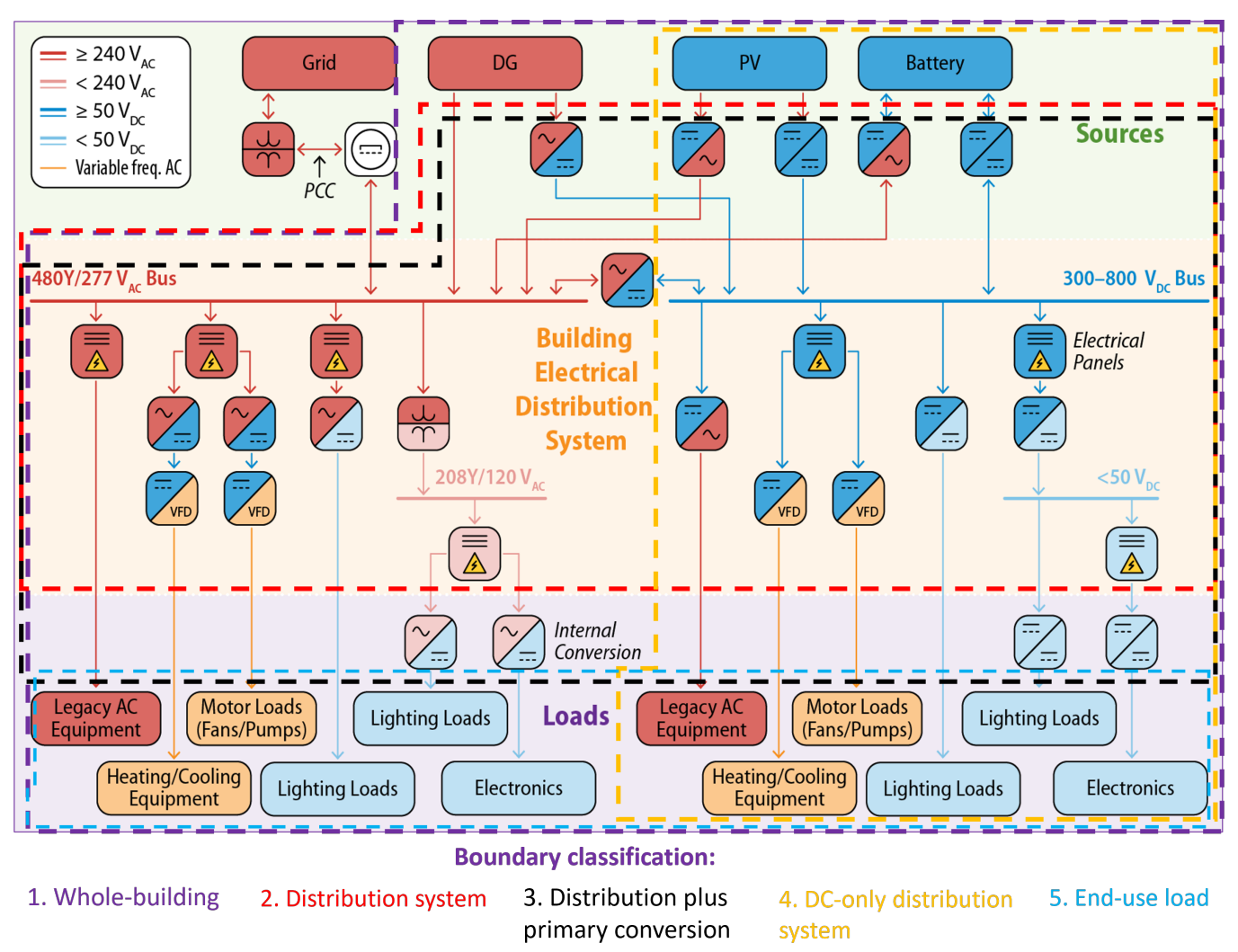

Figure 1. Proposed boundaries for a typical building electrical distribution system. Illustration by Christopher Schwing, National Renewable Energy Laboratory.

The performance metrics developed in the next section are entirely dependent on the selected boundary. For instance, if the purpose is to compare efficiency across buildings where the internal conversion equipment losses of the end-use loads are unknown, the building electrical distribution system boundary excluding the primary conversion stages can be used. However, if the purpose is to evaluate the total losses within a building, the building electrical distribution system boundary plus primary conversion stages should be used.

The boundary allocation procedure described above ensures consistent evaluation or comparison for a broad range of system architectures and enables the benchmarking of electrical distribution technologies across different building types.

\subsection{Metrics Estimation}

This section defines the performance metrics needed to effectively compare different building electrical distribution systems. These metrics are broadly categorized into quantitative and qualitative metrics, as shown in Figure 2. The quantitative metrics are further classified into energy and non-energy metrics. The former includes Power Transfer Effectiveness $(P T E)$, Distribution Loss Function ( $D L F)$, Grid Energy Intensity (GEI), DER Energy Intensity (DEREI), Grid Utilization Fraction (GUF), and DER Utilization Fraction (DERUF). The latter are related to system reliability, resilience, and cost-benefit analysis [21,22]. The qualitative metrics include interoperability and safety, among others [23-25]. Some of these metrics might be harder to quantify (fully or partially) for building-level electrical distribution systems because of the lack of research and data, but they are categorized here for simplicity. This paper discusses in detail the quantitative energy metrics and their appropriate measurement strategies. The non-energy and qualitative metrics are beyond the scope of this paper, and future research work will provide in-depth analysis of these metrics. 


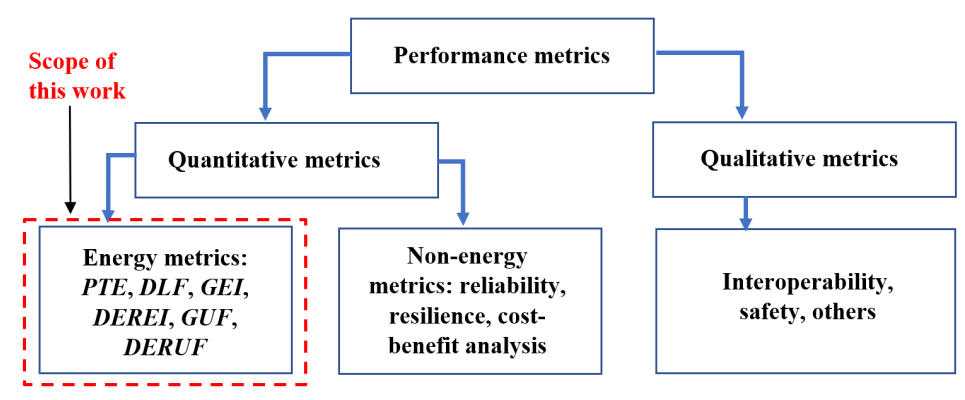

Figure 2. Performance metrics for building-level electrical distribution systems.

i Power Transfer Effectiveness (PTE)

The PTE is used to measure the efficiency of building-level electrical distribution systems. It is the ratio of the total power of existing electrical loads $(L)$ in a building $\left(P_{\text {load }}\right)$ to the total power that is used to serve that load $\left(P_{\text {source }}\right)$, which is expressed as $\eta_{h}$ and shown in Equation (1). Psource includes all the power sources that supply energy to the distribution system: grid $\left(P_{\text {grid_im }}\right), \operatorname{DER}\left(P_{\text {der }}\right)$, and BESS $\left(P_{\text {ess_src }}\right) . P_{\text {load }}$ also includes the power exported to the grid $\left(P_{\text {grid_ex }}\right)$ in case there is on-site generation within the building. A PTE near 1 is desired and can be improved by using more efficient equipment.

$$
\text { PTE }=\eta_{h}=\frac{P_{\text {load }}}{P_{\text {source }}}
$$

where

$$
\begin{array}{r}
P_{\text {source }}=P_{\text {grid_im }}+P_{\text {der }}+P_{\text {ess_src }} \\
P_{\text {load }}=\sum_{l=0}^{L} P_{\text {load }}^{l}+P_{\text {grid_ex }}+P_{\text {ess_load }}
\end{array}
$$

ii Distribution Loss Function (DLF)

The DLF gauges the distribution losses within a building energy system and is calculated as a ratio between the losses and the total power supplied to the building from all the energy sources, as shown in Equation (2). The DLF can never be zero, but it is desired to be as small as possible.

$$
D L F=\frac{P_{\text {source }}-P_{\text {load }}}{P_{\text {source }}}
$$

\section{iii Grid Energy Intensity (GEI)}

The GEI is the ratio of the total energy supplied by the utility grid to a building ( $\left.E_{\text {grid_im }}\right)$ to its total floor area $\left(A_{\text {floor }}\right)$, as shown in Equation (3). It is measured in Wh $/ \mathrm{m}^{2}$. The GEI is used to compare energy utilization across building types (hospitals, offices, shopping centers, etc.).

$$
G E I=\frac{E_{\text {grid_im }}}{A_{\text {floor }}}
$$

iv DER Energy Intensity (DEREI)

Similar to GEI, DEREI quantifies the total energy supplied by DERs to a building $\left(E_{\text {der }}+E_{\text {ess_src }}\right)$ with respect to its total floor area $\left(A_{\text {floor }}\right)$, as shown in Equation (4). It is also measured in $\mathrm{Wh} / \mathrm{m}^{2}$. When a building operates in grid-connected mode, any surplus energy exported to the grid $\left(E_{\text {grid_ex }}\right)$ is excluded from the total energy supplied by DERs for the DEREI calculation, as shown in Equation (4). The DEREI varies among buildings 
according to the installed DER capacity (in the case of PV, this is largely dependent upon the available rooftop space or parking area space for PV installation).

$$
D E R E I=\frac{E_{\text {der }}+E_{\text {ess_src }}-E_{\text {grid_ex }}}{A_{\text {floor }}}
$$

v Grid Utilization Fraction (GUF)

The GUF metric is calculated as the ratio of the total energy supplied by the electric grid $\left(E_{\text {grid_im }}\right)$ to the total energy demand of the building $\left(E_{\text {source }}\right)$, as shown in Equation (5). The GUF metric will become increasingly critical due to future/higher DER and microgrid penetration. The value of GUF can only be zero when the building operates as a microgrid or when the DER (PV, DG, BESS) generation equals or exceeds the building load.

$$
G U F=\frac{E_{\text {grid_im }}}{E_{\text {source }}}
$$

vi DER Utilization Fraction (DERUF)

DERUF was developed to account for the energy contribution of DERs in a building's total energy demand, as shown in Equation (6).

$$
D E R U F=\frac{E_{\text {der }}+E_{\text {ess_src }}-E_{\text {grid_ex }}}{E_{\text {source }}}
$$

The quantitative energy metrics are summarized in Table 1.

Table 1. Summary of proposed metrics.

\begin{tabular}{ccl}
\hline Metric & Equation & Definition \\
\hline PTE & $\eta_{h}=\frac{P_{\text {load }}}{P_{\text {source }}}$ & $\begin{array}{l}\text { Ratio of total power from electrical end- } \\
\text { use loads in a building }\left(P_{\text {load }}\right) \text { to the total } \\
\text { power used to serve that load }\left(P_{\text {source }}\right) .\end{array}$ \\
\end{tabular}

\section{Significance}

Measures the efficiency of building-level electrical distribution systems. Ranges from 0 (no load in distribution system) to 1 (all source power is consumed by the load).

Measures the losses within a distribution

DLF $\quad \frac{P_{\text {source }}-P_{\text {load }}}{P_{\text {source }}}$

Ratio of losses $\left(P_{\text {source }}-P_{\text {load }}\right)$ to the total power supplied to the building $\left(P_{\text {source }}\right)$.

Ratio of total energy supplied by the utilGEI $\quad \frac{E_{\text {grid_im }}}{A_{\text {floor }}}$ ity grid to a building ( $\left.E_{\text {grid_im }}\right)$ to its total floor area $\left(A_{\text {floor }}\right)$. Measured in $\mathrm{Wh} / \mathrm{m}^{2}$. system. Ranges from 0 (all source power goes to distribution system loss) to 1 (no losses in the distribution system).

Used for standardization of grid-DER mix for different building types.

Ratio of total energy supplied by DERs to a DEREI $\frac{E_{\text {der }}+E_{\text {ess_src }}-E_{\text {grid_ex }}}{A_{\text {floor }}}$ building $\left(E_{\text {der }}+E_{\text {ess_src }}-E_{\text {grid_ex }}\right)$ to its total floor area $\left(A_{\text {floor }}\right)$. Measured in $\mathrm{Wh} / \mathrm{m}^{2}$.

Used for standardization of grid-DER mix for different building types.

Measures the grid energy share to total energy consumed in the building. Ranges from 0 (no energy consumed from the utility grid) to 1 (only utility grid energy consumed).

grid to a bulal energy supplied by the utility energy building ( $E_{\text {grid_im }}$ ) to the

Measures the share of the DERs to total

Ratio of total energy supplied by DERs to DERUF $\frac{E_{\text {der }}+E_{\text {ess_src }}-E_{\text {grid_ex }}}{E_{\text {source }}}$ a building $\left(E_{d e r}+E_{\text {ess_src }}-E_{\text {grid_ex }}\right)$ to the building's total energy demand ( $\left.E_{\text {source }}\right)$. energy consumed in the building. Ranges from 0 (no energy consumed from DERs) to 1 (only DER energy consumed).

The performance metrics developed here, along with well-defined boundaries, can be used to compare commercial and residential buildings. In the next section, these performance metrics are evaluated for a benchmark commercial building model. 


\section{Case Study}

This section presents a case study to illustrate the performance metrics evaluation approach proposed in the previous section. In particular, this case study looks at an updated version of the CRBM presented in [26]. Although the approach is evaluated on a commercial office building, it is equally applicable to residential, industrial, or other building types. The CRBM, similar to typical commercial buildings [27], uses a three-phase AC distribution at $480 \mathrm{Y} / 277 \mathrm{~V}$ and $208 \mathrm{Y} / 120 \mathrm{~V}$. The $480 \mathrm{Y} / 277 \mathrm{~V}$ system serves the major mechanical and lighting loads, while the $208 \mathrm{Y} / 120 \mathrm{~V}$ system serves the smaller plug loads. This model provides building energy stakeholders with a reference for further analysis and comparison. This model is based on a medium-size office building from 1980 to 2000 that was inherently AC. To apply the proposed approach to all existing and future buildings, we also transformed the model into a hybrid AC/DC system through the integration of a rooftop PV system and DC-native loads. For the case study, the building electrical distribution system plus primary conversion stage boundary was used. The details of the individual AC and hybrid AC/DC systems are presented in subsequent sections.

\subsection{AC Distribution System Models}

We revised the CRBM to represent a typical modern-day commercial building electrical distribution system running primarily on AC. The modifications included adding converterinverter pairs that represent the lumped variable frequency drives associated with elevator motors and rooftop units (RTUs). In addition, energy-efficient light-emitting diodes (LEDs) replaced the fluorescent lighting within the building and the high-intensity discharge (HID) lamps in the parking lot ( $250 \mathrm{~W}$ each). Originally, there were 252 fluorescent lights on each floor, which were distributed as 14 lights on each of the 18 circuits. They were replaced with 252 LEDs ( $42 \mathrm{~W}$ each), which use 2.7 times less energy. Each of the existing lighting circuits was rated to handle $\sim 75$ LEDs; therefore, the internal lighting circuits on each floor were reduced from 18 to four (in which each circuit energizes 63 LEDs). The same approach was employed for the external lighting, which consisted of 60 HIDs with 10 HIDs on each of the six circuits. Each circuit is capable of handling 20 LEDs (110 W each). Next, three circuits were employed to handle all 60 LEDs, with 20 LEDs on each circuit. This ultimately reduces the number of exterior lighting circuits from six to three. Since the case study uses the building electrical distribution system plus primary conversion stage boundary, the LED drivers are included in the distribution system boundary instead of the load boundary. The modified AC electrical distribution system CRBM is depicted in Figure 3.

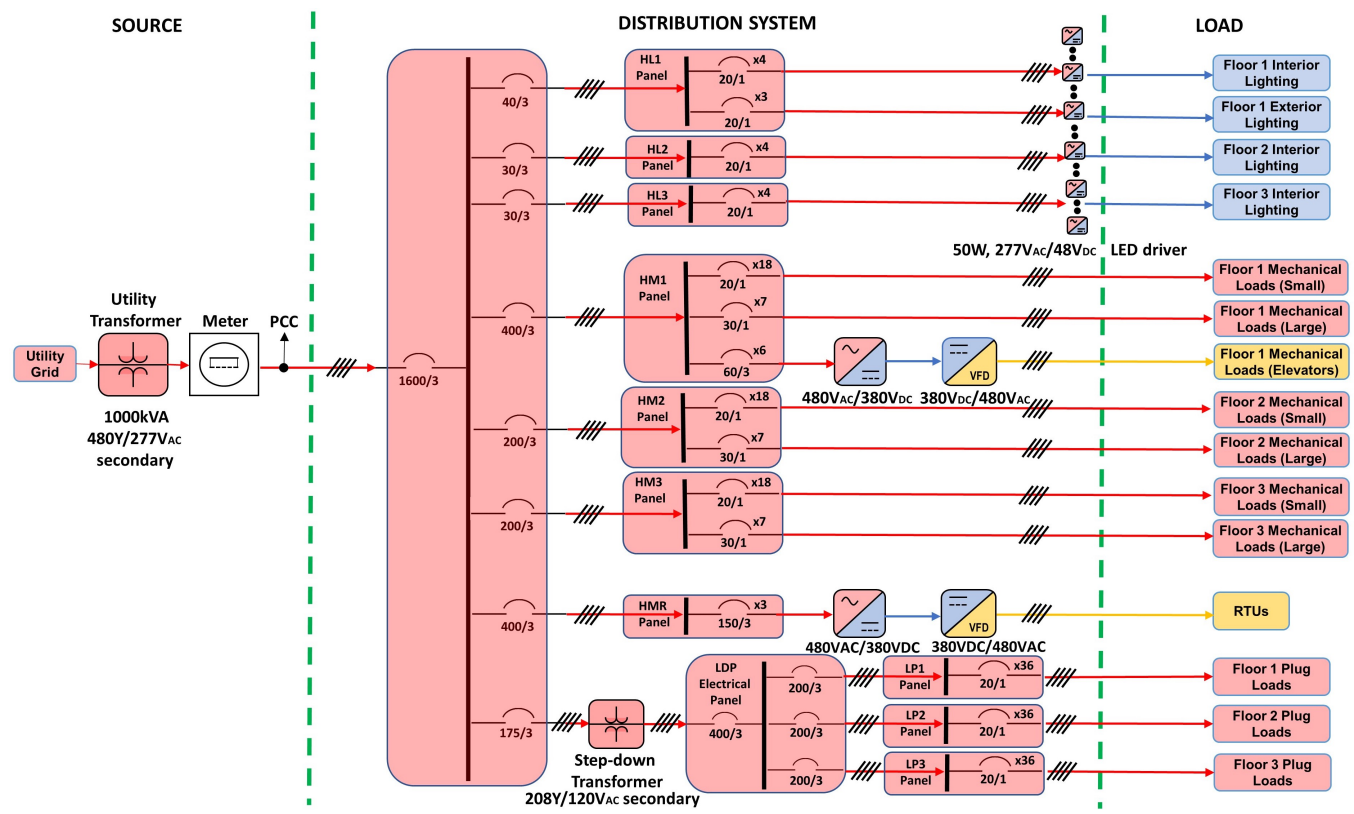

Figure 3. Modified AC electrical distribution system CRBM. 
The AC electrical distribution system was further altered to incorporate the increasing trend of clean energy utilization in the building energy supply. A $70 \mathrm{~kW}, 380 \mathrm{~V}$ rooftop PV system occupying an area of $368.42 \mathrm{~m}^{2}$ was integrated into the CRBM. The PV system was sized to fit into the available rooftop area and to power the lighting load. The PV system was directly integrated into the MHDP panel using a bidirectional converter. The surplus energy from the PV system serves other loads in the building or is exported to the utility. Figure 4 shows the resultant distribution system.

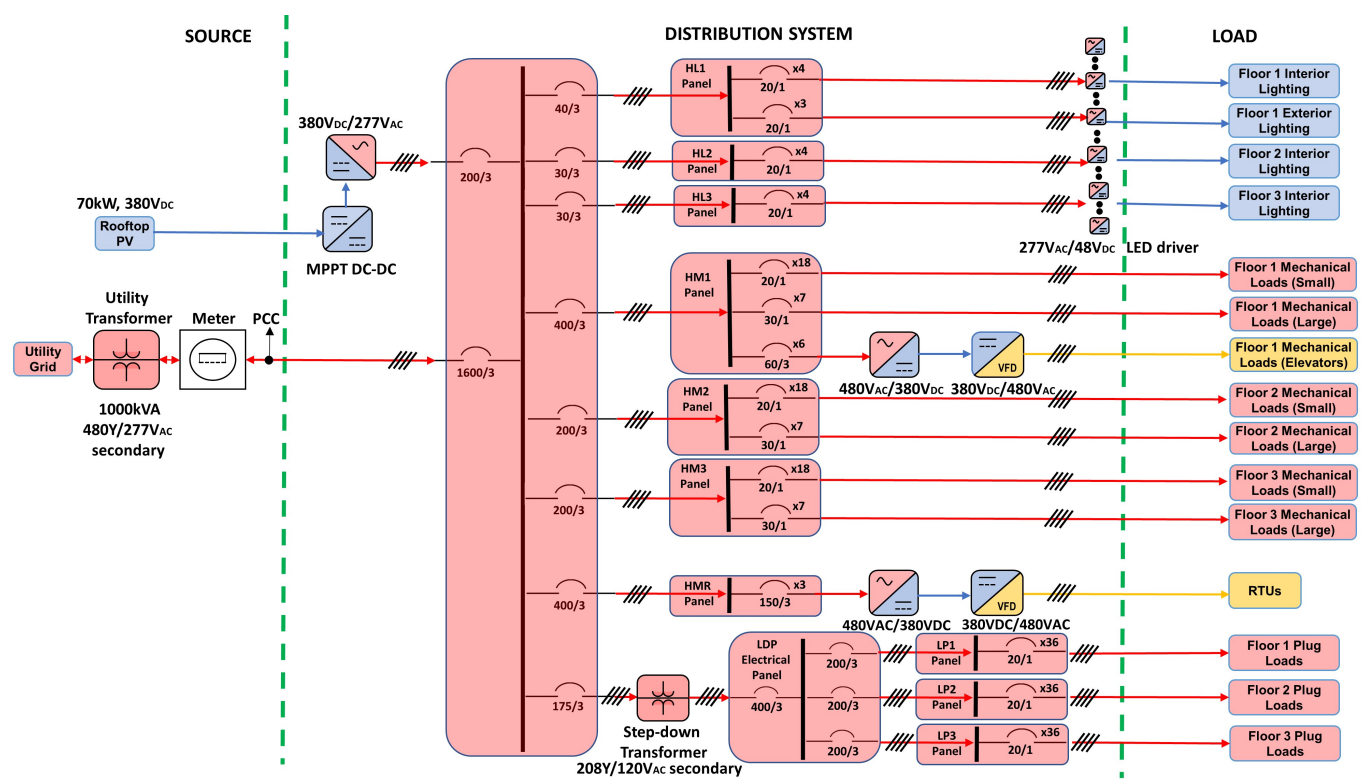

Figure 4. Modified AC electrical distribution system CRBM with rooftop PV.

\subsection{Hybrid AC/DC Distribution System Model}

The AC electrical distribution shown in Figure 4 was further transformed into a hybrid AC/DC system. It was modified to meet current building standards and to keep the alteration cost down. Here, the PV system was directly integrated into the lighting load section using a $380 \mathrm{~V}_{D C} / 48 \mathrm{~V}_{D C}$ DC-DC converter. The PV system was also connected to the utility grid through the same bidirectional converter, which exports PV power during overproduction and imports power during underproduction. The rest of the system is similar to the modified AC distribution system presented in Figure 4. The developed hybrid AC/DC electrical distribution system is shown in Figure 5.

Table A1 in the Appendix A lists all the converters used in the building electrical distribution system analysis. Instead of assuming constant converter efficiency at all loading levels, as in previous works $[12,13,16,17]$, we used efficiency curves from the manufacturers to represent the actual performance of these power electronic converters at different loading levels. We obtained these converter efficiency curves from data uploaded on the California Energy Commission website [28]. As an example, the efficiency curve for an elevator rectifier (Murata D2U5T) is shown in Figure A1. 


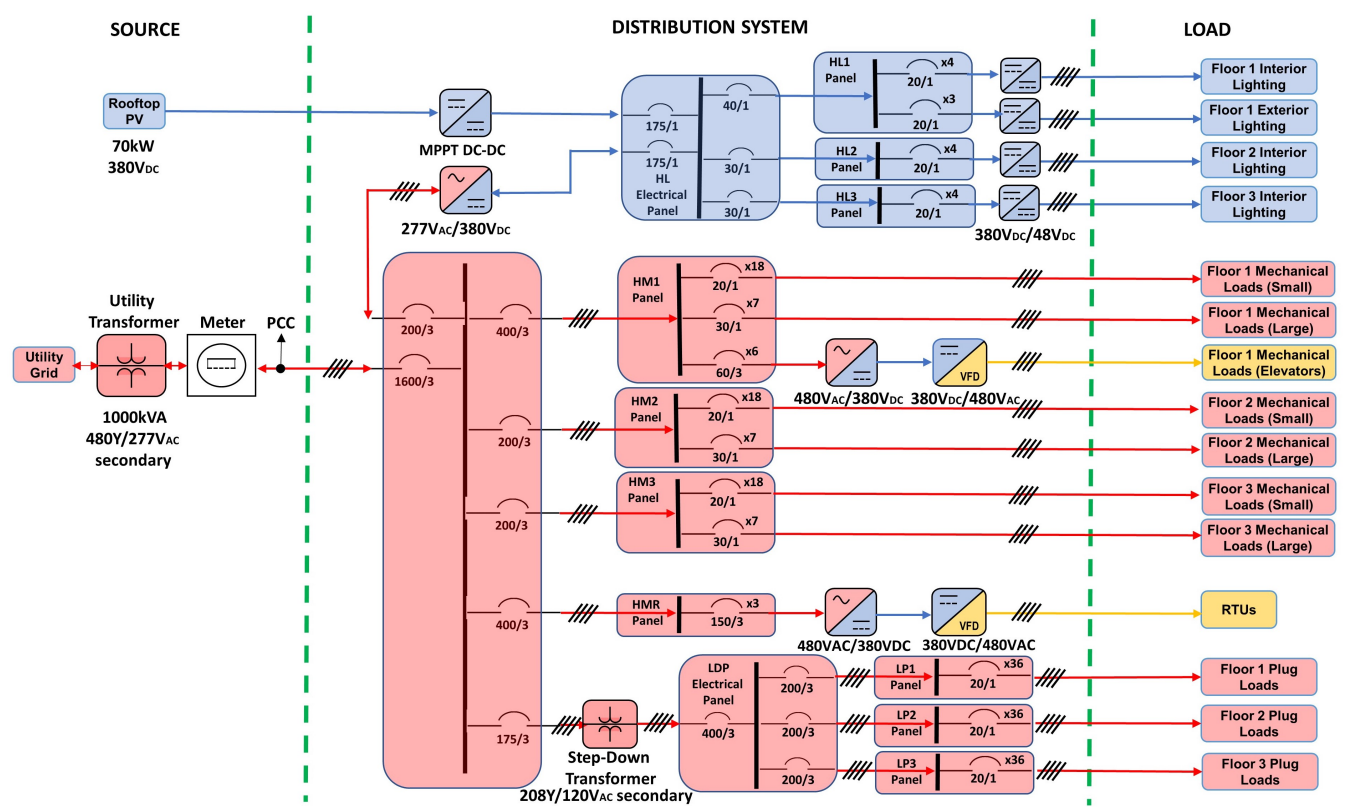

Figure 5. Modified hybrid AC/DC electrical distribution system CRBM.

\section{Simulation Results}

We computed performance metrics for the CRBM to illustrate its use. Our evaluation strategy incorporates equipment efficiencies, conversion losses, distribution system losses, and the net effect of on-site generation. The load data used for this case study are hourly data simulated over a year using EnergyPlus ${ }^{\circledR}$ [29]. In order to give an idea of building load composition, the whole-year daily average consumption of various distribution system components for the AC system without PV is shown in Figure 6. The hourly load consumption of the components for the first weeks of January and June are shown in Figure 7 and Figure 8, respectively, to illustrate seasonal demand variations. The RTUs have higher demand during summer due to cooling requirements. On the other hand, the mechanical load is smaller during the summer because the mechanical load comprises elevators and reheat coils. The elevators have relatively uniform consumption throughout the year, but the reheat coils have higher utilization during the winter due to increased heating requirements. Solar energy hourly production data for the AC with PV and hybrid AC/DC systems were generated using the National Renewable Energy Laboratory's PVWatts ${ }^{\circledR}$ calculator [30] for the Seattle, Washington, area. The overall building-level electrical distribution systems were modeled using the Python scripting language, and Table 2 presents the associated results.

For all three distribution systems, PTE drops during the summer because of the significantly higher losses from the RTU converters due to the increased cooling requirement. The loss profile of various distribution system components for the AC system without PV is shown in Figure 9. For the hybrid AC/DC system, the PTE is lower throughout the year. This is due to additional losses in the solar bidirectional converter, resulting from substantial power export to the grid or to the other loads (except lighting) during surplus PV generation and low lighting demand. During lower PV generation hours, the grid also feeds the lighting section through a similar bidirectional converter, which increases losses and lowers PTE. The PTE of an AC system with PV is also lower than that of an AC system without PV during the day, when the PV system generation is higher, leading to more losses in the solar bidirectional converter. The DLF of the three considered systems is computed and presented in Table 2. As expected, PTE and DLF are highly correlated; an increase in one leads to a drop in the other and vice versa, as observed by comparing the $D L F$ for the distribution systems. 


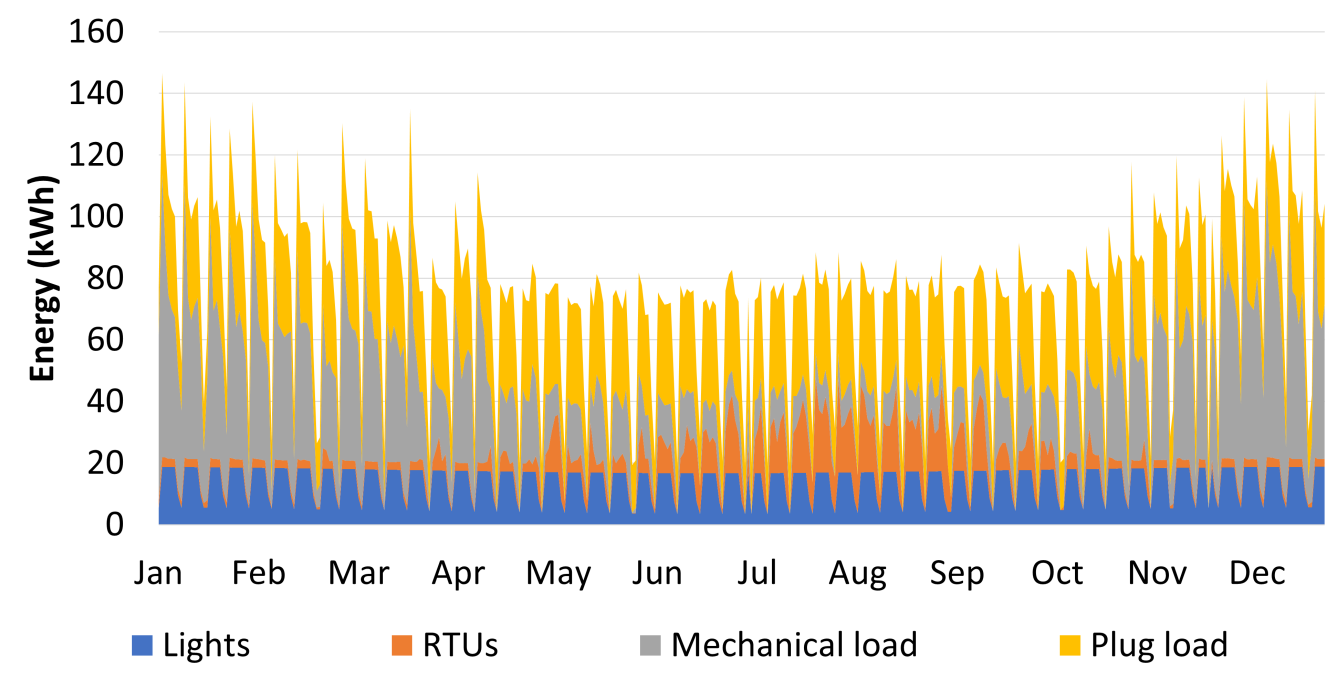

Figure 6. Yearly load profile (daily average) for different building components.

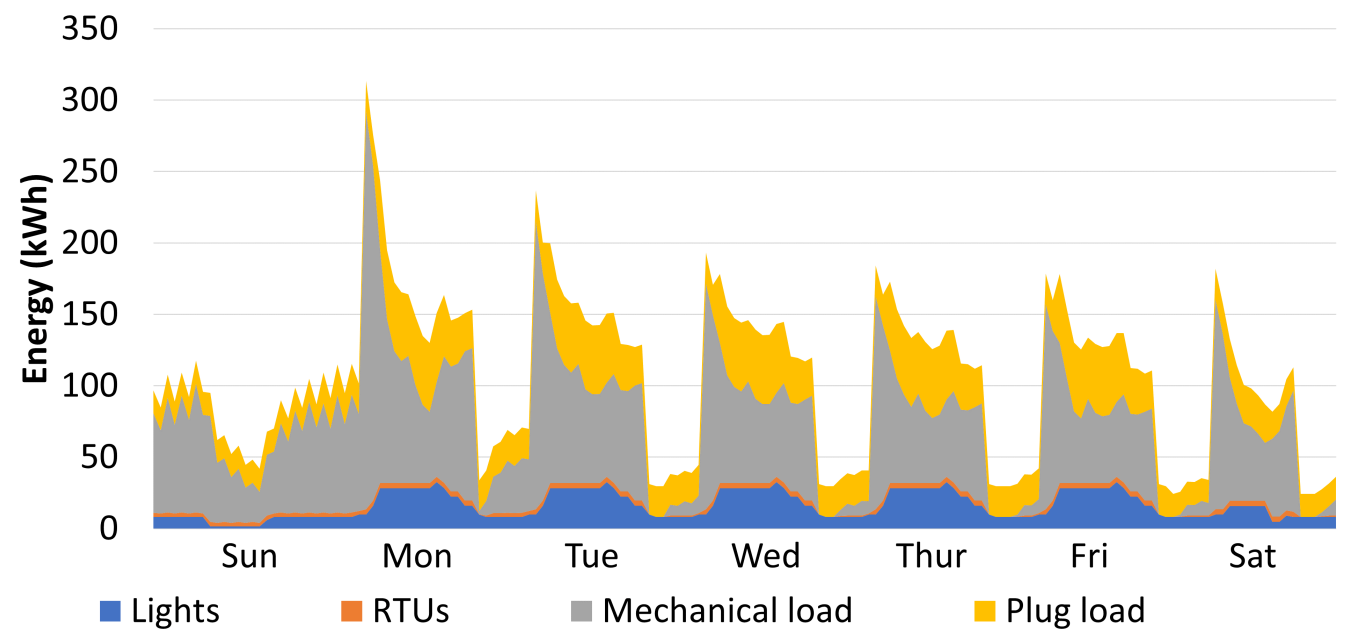

Figure 7. Hourly load profile of different building components for a week in January.

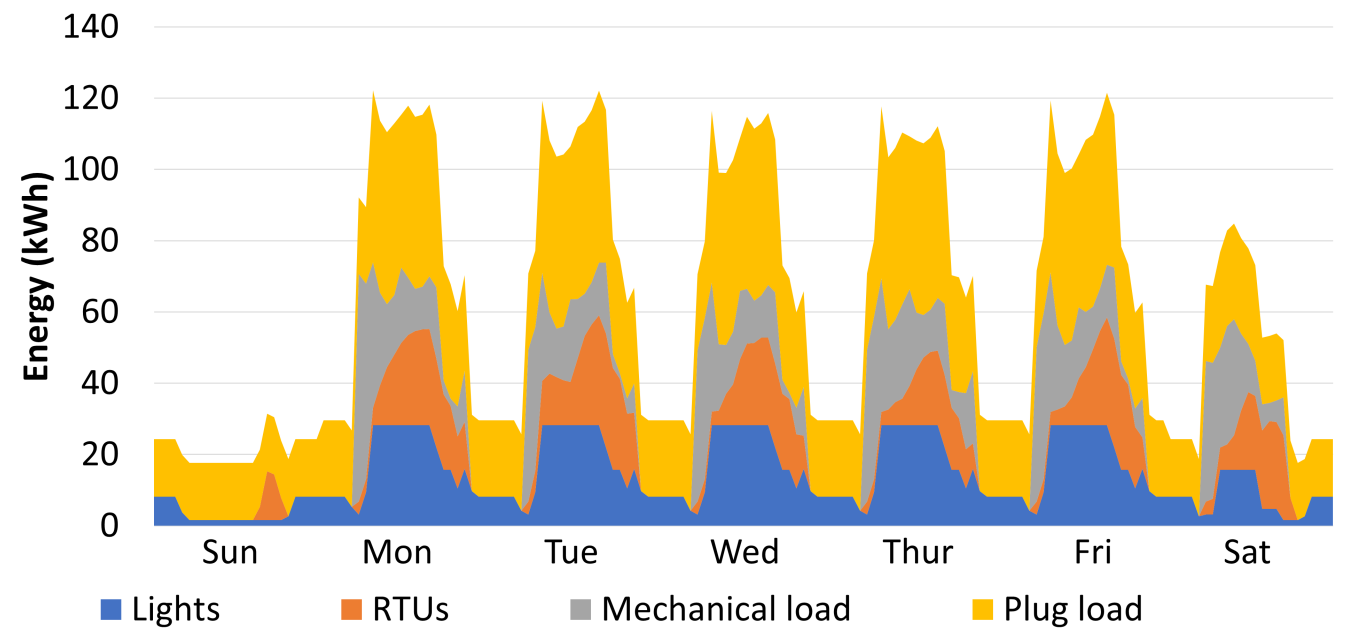

Figure 8. Hourly load profile of different building components for a week in June. 


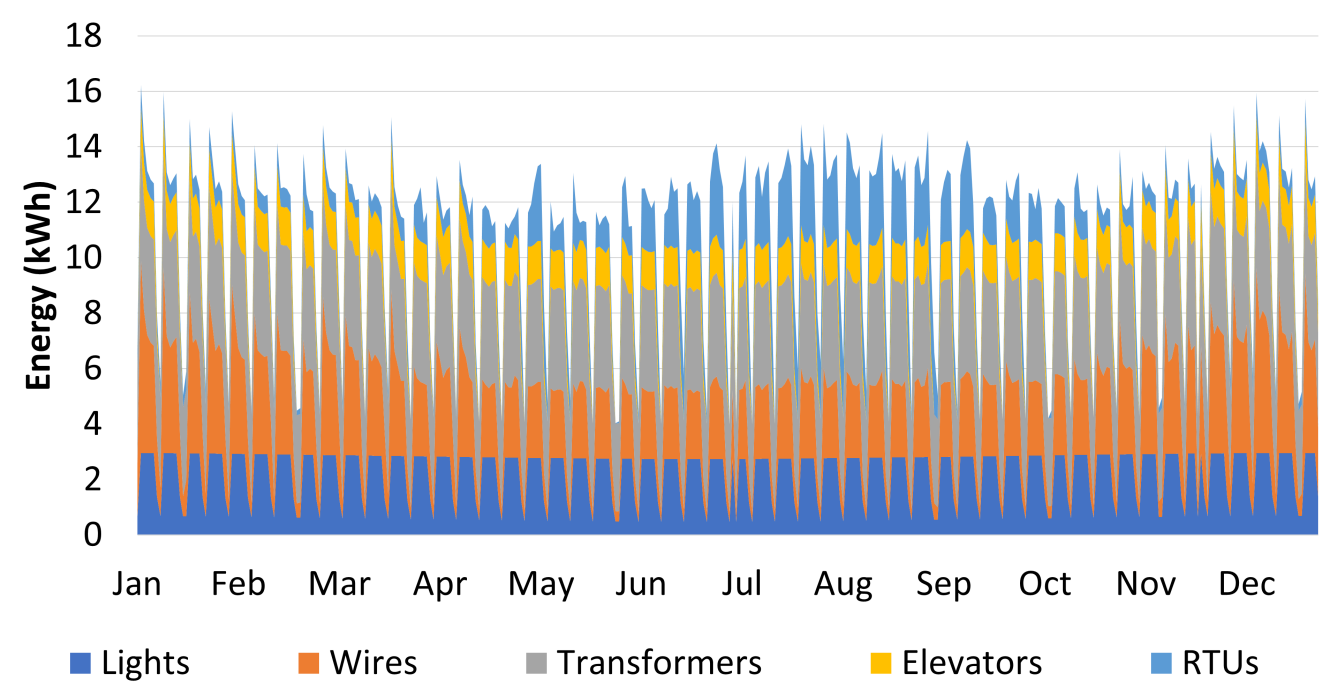

Figure 9. Yearly loss profile (daily average) of different building components.

Next, we compute and evaluate the GUF for the AC and hybrid systems. As the grid is the only energy source for the modified AC system without PV, it serves all the energy demands of the building; therefore, the GUF for this system is 1 . In the case of the AC with $\mathrm{PV}$ and hybrid AC/DC systems, the energy contribution from the grid relative to the total energy demand of the building falls during the summer, when the rooftop PV system is generating the most energy. This ultimately brings the GUF down. For the same reason, the $D E R U F$ for these systems is observed to be higher during the summer as compared to the rest of the year. Another important metric to compare across buildings is the GEI. Similar to the GUF, for the AC with PV and hybrid AC/DC systems, the GEI falls substantially during the summer as the DERs increase as a share of the total building energy demand. Similarly, the DEREI increases during the summer due to higher generation from the rooftop PV.

To depict the effect of more generation from the on-site PV system during the summer as compared to the winter, the proposed metrics are also computed and compared for a typical week in January and June. Table 3 shows a decrease in PTE during the summer due to more losses in the RTU converters, as previously discussed. For the hybrid system, the PTE is substantially lower during weekend afternoons in June, when the PV generates more than the lighting section requirement. This leads to a considerable flow to the other loads of the building or to the grid through the bidirectional converter, which enhances the overall system loss. This is also confirmed by higher DLF at the respective low PTE hours. Similarly, we also compared the GUF and DERUF for January and June. A GUF plot closer to 1 is observed in January. This indicates that the grid serves the majority of the building load during January, when there is limited PV generation. On the other hand, the share of the PV in the total building demand increases significantly during June, which ultimately decreases the grid share of the total energy requirement of the building. This is represented by a DERUF plot that has higher values for June. Particularly during weekend afternoons in June, when the building is unoccupied and PV generation is at its peak, the on-site PV production is sufficient to meet the overall building load. This leads to a GUF value of 0 and a DERUF value equal to 1 . Similarly, we computed and compared the GEI and DEREI for January and June, revealing a similar trend as for the GUF and DERUF. 
Table 2. Metrics variation comparison for different configuration ( $y$-axis = time of day).

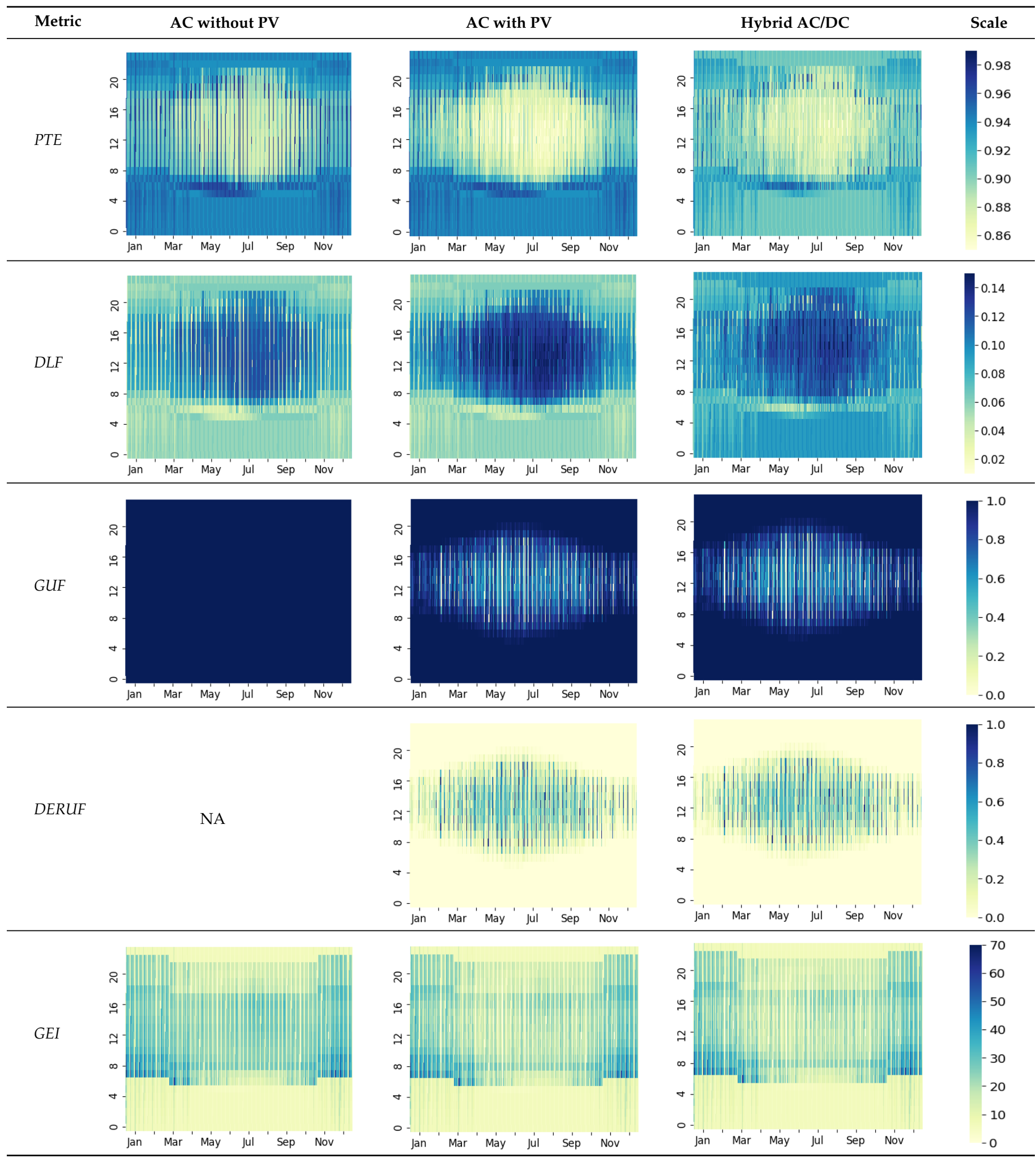


Table 2. Cont.

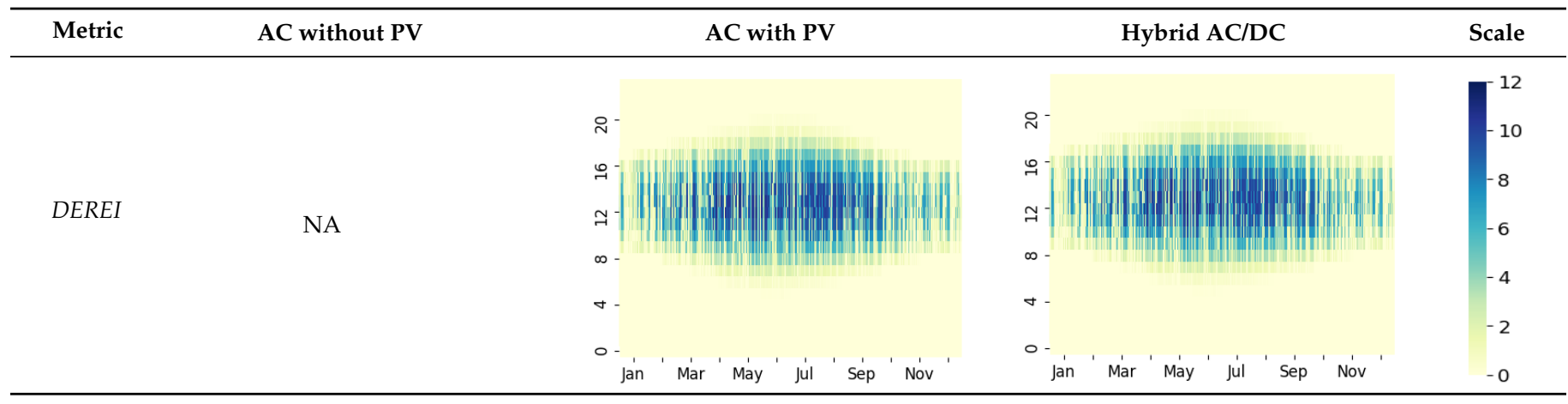

Table 3. Seasonal variation of metrics for the AC and hybrid building electrical distribution systems.

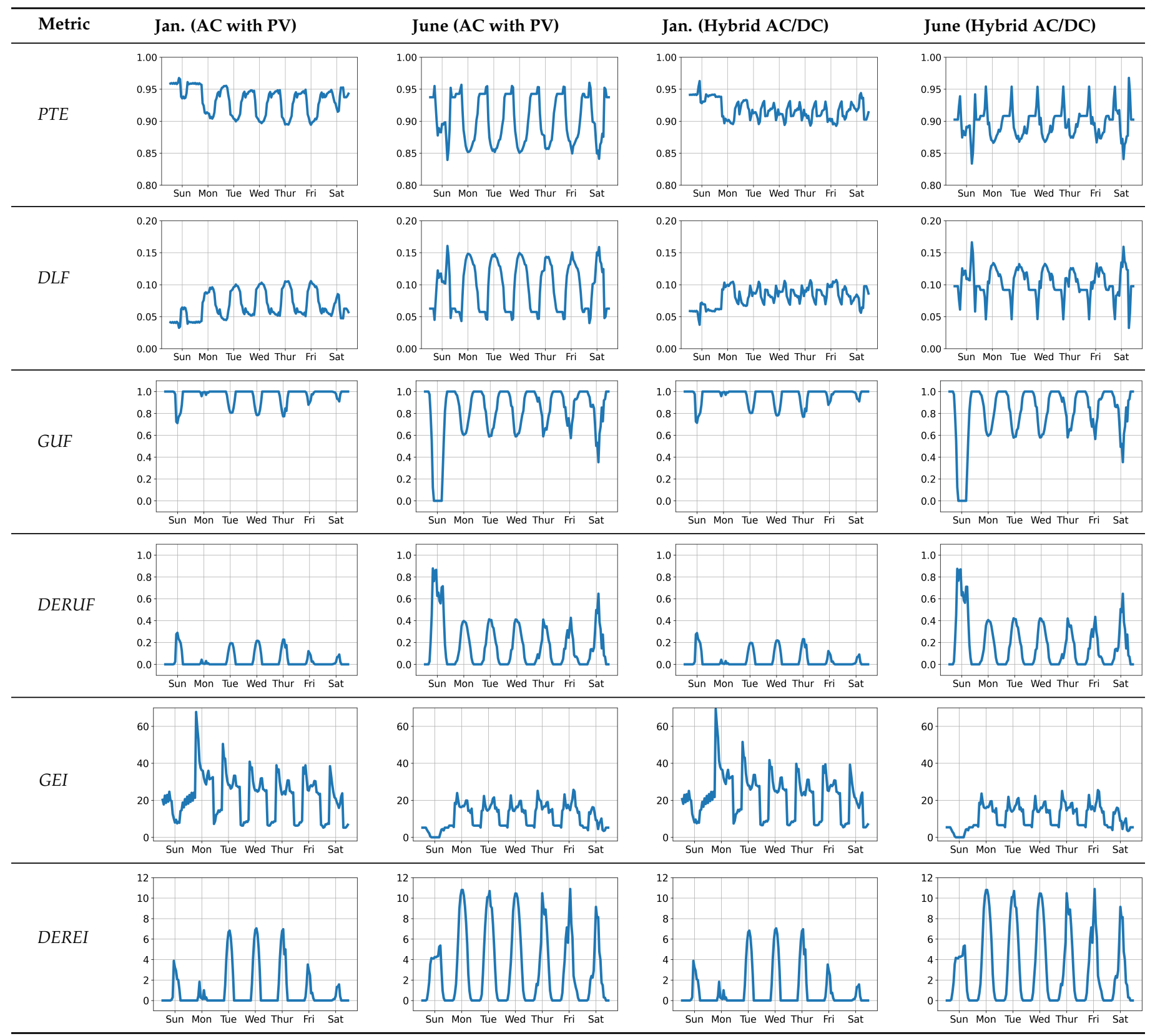




\section{Discussion}

The proposed metrics and associated computation strategies presented in the previous sections provide the framework for building a research and design community to perform a detailed comparative analysis of AC, DC, and hybrid AC/DC systems. These metrics also support the decision-making process by providing data on incorporating specific building designs and implementing proper amelioration strategies. The appropriate building boundary and performance metrics for a specific application should be selected depending on the evaluation objectives. For instance, if the efficiency of the equipment is of interest, the end-use load boundary can be used, whereas if the distribution system performance is of interest, the distribution system boundary can be used (with the appropriate developed metrics). Similarly, to evaluate and compare the performance of AC and DC equipment within a building for a hybrid distribution system, the AC-only and DC-only distribution network boundary can be utilized. The whole-building boundary can be selected when measuring the overall building performance in terms of efficiency, reliability, power quality, and other metrics. To illustrate the significance of the proposed building electrical distribution system boundaries, we compared the PTE of the three considered distribution systems for two boundaries (building electrical distribution system and building electrical distribution system plus primary conversion stage). The computed PTE metric is listed in Table 4 . We observe that using two different boundaries leads to considerably different PTE values for the AC systems, because the LED drivers are also considered part of the load for the distribution system boundary as opposed to the distribution system plus primary conversion stage boundary. This ultimately leads to higher values of PTE for the distribution system boundary.

Table 4. PTE comparison for different building boundaries.

\begin{tabular}{cccc}
\hline Considered Boundary & AC without Solar & AC with Solar & Hybrid AC/DC \\
\hline Distribution system & $95.36 \%$ & $94.34 \%$ & $90.46 \%$ \\
\hline Distribution plus primary conversion & $92.60 \%$ & $91.62 \%$ & $90.46 \%$ \\
\hline
\end{tabular}

The different proposed metrics can also be used in different ways depending on the distribution system evaluation objective. For instance, the PTE and DLF can be used to gauge the requirement for energy-efficient technologies or strategies within a building. If we observe that the PTE of an electrical distribution system decreases significantly during the low loading of converters, we can analyze whether single or multiple parallel converters - each operating within their optimum operation limit—are required. Similarly, the GUF and DERUF can be used for optimum DER sizing within the building, where the objective is to minimize the bidirectional grid flows that are associated with significant energy losses. In turn, this leads to efficient energy consumption within the building, lower energy bills for customers, and potentially fewer emissions. The GEI or DEREI metrics are also an effort toward the standardization of a grid-DER mix for different building types, such as hospitals, commercial buildings, shopping malls, warehouses, apartment complexes, and even independent homes.

The simulation results show that the PTE of the AC system without PV is the highest, which is followed by the AC with PV and hybrid AC/DC systems. The whole-year energy loss of the various components within the building electrical distribution systems are plotted in Figure 10.

The three electrical distribution systems considered in this study are only studied for metric analysis and do not represent the optimized version of each topology. We observed that the AC system with PV had a noticeable additional loss from the solar bidirectional converter when compared with the AC system without PV. This brings the overall PTE of the AC system with PV lower than that of the AC system without PV. Similarly, the solar bidirectional converter in the hybrid AC/DC system has significantly higher losses due to substantial export to the grid or to the rest of the loads in the building during low 
demand hours of the lighting section. Moreover, power import from the grid during hours when the on-site PV system is unable to serve the lighting load section also contributes to the solar bidirectional converter losses. The lighting section has lower demand from the grid during the daytime, when the PV system has higher generation, and vice versa. This is the ultimate cause of the hybrid AC/DC system having the lowest PTE of the three electrical distribution systems. One way to enhance the PTE of the hybrid AC/DC system is to reduce the two-way power flow and, ultimately, the losses of the solar bidirectional converter. This can be realized by coupling the PV system with a reasonably sized BESS. From the perspective of future building electrical distribution systems, the losses of the hybrid AC/DC system can be further reduced by coupling the DC side of the variable frequency drive converters associated with the elevators and RTUs directly to the DC bus. This will remove the requirement of the associated rectifier stage and will significantly drop the overall building energy loss from the hybrid AC/DC electrical distribution systems.

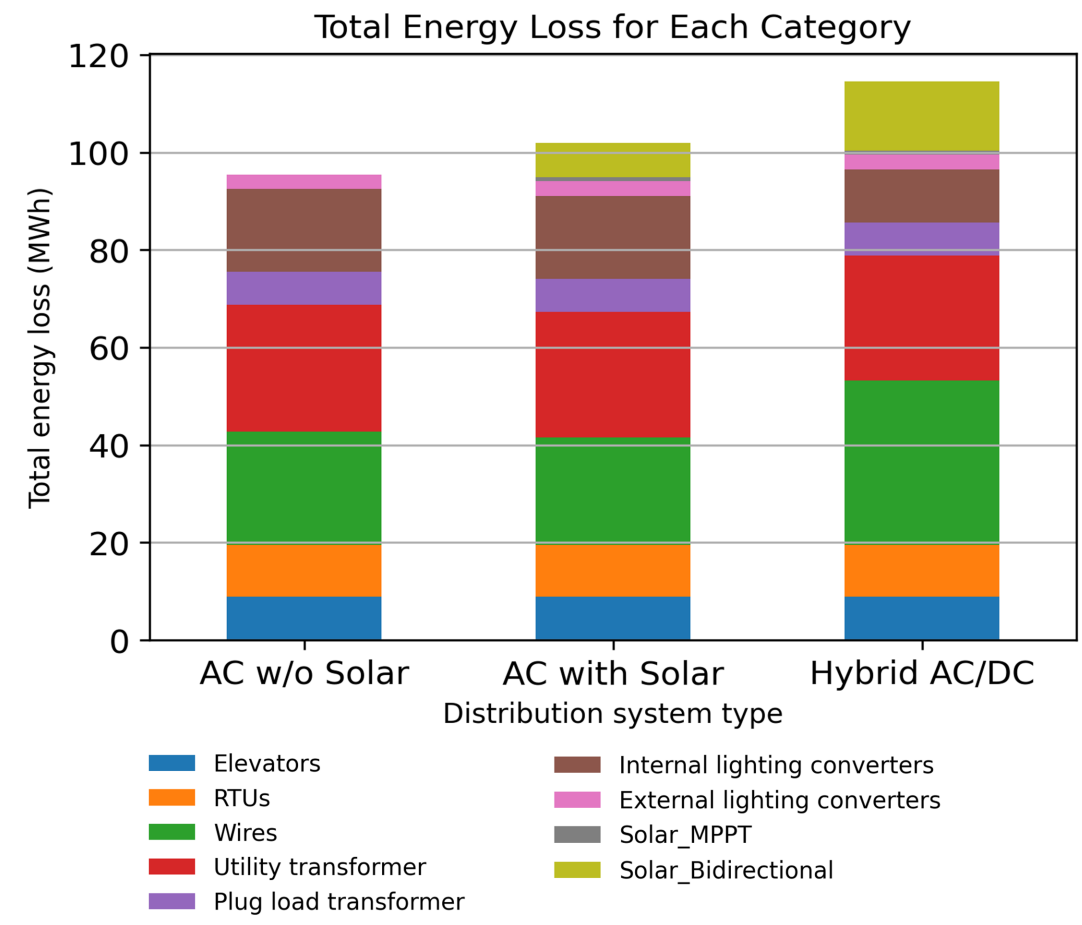

Figure 10. Whole-year loss comparison for the three building electrical distribution systems.

The precise computation of the proposed metrics in this work is highly dependent on the accuracy and proper calibration of the metering equipment. Current transformers and voltage transformers are typically used for current and voltage measurements within a building. Proper sizing of the transformers is important, as their accuracy can otherwise decrease significantly below their rated values. Similarly, proper clamping and consistent core gap enhance the accuracy of the measured variables. Current transformers and voltage transformers, similar to traditional transformers, are also prone to half-cycle saturation caused by significant DC offset in the primary measured variable. This leads to a lowerthan-actual value observed on the secondary side. The errors introduced by inappropriate equipment calibration, improper current transformer sizing and core gap, and low precision can accumulate, leading to large variations in the measured results. It is not always viable to gather measurements from every node within a building because of accessibility or financial constraints. In such scenarios, the models can be refined by available measurements, and additional data can be obtained via extrapolation, data sheets, literature review, or other sources. However, such techniques are highly prone to errors from inaccurate system modeling. Therefore, the developed models should be highly precise and robust against modeling uncertainties. 


\section{Conclusions and Future Work}

This paper motivates the need for a standard system of metrics and methods to describe, quantify, and compare the performance of electrical distribution systems across building types, applications, and sizes. It also proposes standardized boundaries and performance metrics for the universal comparison of building-level distribution systems. The case study presents a practical example that illustrates the utilization of the proposed boundaries and metrics for a common office building. The simulation results show higher efficiencies for the $\mathrm{AC}$ without solar configuration than the $\mathrm{AC}$ with solar and the hybrid AC/DC configurations. Figure 10 shows the energy losses for the equipment and pinpoints shortcomings for each topology. This analysis framework can be used to optimize each version of the topology. Through the proposed method, we can effectively and uniformly compare distribution systems and assess their power transfer efficacy. The proposed method will facilitate technology adoption by providing consistent metrics, thus enabling reliable performance predictions so building stakeholders can better design and optimize construction projects. Future work will optimize selected building energy systems using the boundaries and performance metrics defined herein. This will involve optimal DER sizing and resource allocation to effectively use local generation while ensuring the reliability and availability of quality power to customers. In addition, this paper only covers energy metrics. Future work will include the study and development of non-energy metrics, including power quality, reliability, and cost-benefit analysis. Our ongoing work includes technology demonstration studies for building-level electrical distribution systems. Data gathered from those efforts will allow us to further evaluate the metrics in real-world settings.

Author Contributions: Research contributions of the authors are as follows: Conceptualization, W.B.H., O.G.; Methodology, O.G., W.B.H., M.N., A.S., C.W.; Formal Analysis, O.G., W.B.H., M.N., C.W.; Software, M.N., C.W., D.G.; Writing-Original Draft, M.N., O.G., W.B.H.; Writing—Review and Editing, D.G.; Visualization, M.N., O.G., A.S., C.W.; Resources, D.G. All authors have read and agreed to the published version of the manuscript.

Funding: This work was authored in part by the National Renewable Energy Laboratory, operated by Alliance for Sustainable Energy, LLC, for the U.S. Department of Energy (DOE) under Contract No. DE-AC36-08GO28308 and in part by Lawrence Berkeley National Laboratory, operated for the DOE under Contract No. DE-AC02-05CH11231. Funding was provided by the U.S. Department of Energy Office of Energy Efficiency Building Technologies Office. The views expressed in the article do not necessarily represent the views of the DOE or the U.S. Government. The U.S. Government retains and the publisher, by accepting the article for publication, acknowledges that the U.S. Government retains a nonexclusive, paid-up, irrevocable, worldwide license to publish or reproduce the published form of this work, or allow others to do so, for U.S. Government purposes.

Institutional Review Board Statement: Not applicable.

Informed Consent Statement: Not applicable.

Data Availability Statement: We obtained converter efficiency curves from data uploaded on the California Energy Commission website [28].

Acknowledgments: The authors would like to extend their gratitude to Dusan Brhlik (Direct Energy Partners) for his technical input, Arthur Santos (Colorado State University) for generating AC LED driver efficiency graphs, Christopher Schwing (NREL) for preparation of graphics, and Susannah Shoemaker (NREL) and Amy Brice (NREL) for editing the manuscript.

Conflicts of Interest: The authors declare no conflict of interest. The funders had no role in the design of the study; in the collection, analyses, or interpretation of data; in the writing of the manuscript; or in the decision to publish the results.

\section{Appendix A}

The converters utilized in the building electrical distribution system models are presented in Table A1. 
Table A1. Converters utilized in the building electrical distribution system models (AC and hybrid AC/DC buildings).

\begin{tabular}{|c|c|c|c|c|c|c|}
\hline Load Type & System & Manufacturer & Part Number & $\mathrm{V}_{\text {in }}(\mathrm{V})$ & $\mathrm{V}_{\text {out }}(\mathrm{V})$ & $P_{\max }(\mathbf{k W})$ \\
\hline \multirow{2}{*}{ Interior Lighting } & AC & Osram & Oti- 48 & $277 \mathrm{AC}$ & $48 \mathrm{DC}$ & 0.048 \\
\hline & Hybrid & SynQor & BQ4H480FTx64 & $380(230-400) \mathrm{DC}$ & $48 \mathrm{DC}$ & 3.04 \\
\hline \multirow{2}{*}{ Exterior Lighting } & AC & Murata & MVAB120 & $277 \mathrm{AC}$ & $48 \mathrm{DC}$ & 0.12 \\
\hline & Hybrid & Emerson & C $400 / 48-3500 \mathrm{e}$ & $380(260-400) \mathrm{DC}$ & $48 \mathrm{DC}$ & 3.5 \\
\hline \multirow{2}{*}{ Elevators } & \multirow{2}{*}{ AC/Hybrid } & Murata & D2U5T & $480(320-528)$ AC3LL & $380(290-400) \mathrm{DC}$ & 5 \\
\hline & & Eltek & 3.8HE-t UL & $360(230-500) \mathrm{DC}$ & 208 AC3LL & 3.8 \\
\hline \multirow{2}{*}{ RTUs } & \multirow{2}{*}{ AC/Hybrid } & CET Power & Sierra 25 & $480(260-530)$ AC3LL & $380(290-600) \mathrm{DC}$ & 30 \\
\hline & & $\mathrm{ABB}$ & TRIO-27.6-TL-OUTD-US-480 & 715 (200-950) DC & 480 AC3LL & 27.6 \\
\hline \multirow{2}{*}{$\begin{array}{c}\text { Solar (MPPT) } \\
\text { Solar (Bidirectional) }\end{array}$} & \multirow{2}{*}{ AC/Hybrid } & Foshan SC Power & SC-MH MPPT 40A & $380(110-380)$ DC & $240(96-240) \mathrm{DC}$ & 11.04 \\
\hline & & Rhombus Energy Solutions & RES-BESS60DP-480 & 480 AC3LL & $441(270-870)$ DC & 59.789 \\
\hline
\end{tabular}

The elevator rectifier efficiency curve is presented in Figure A1.

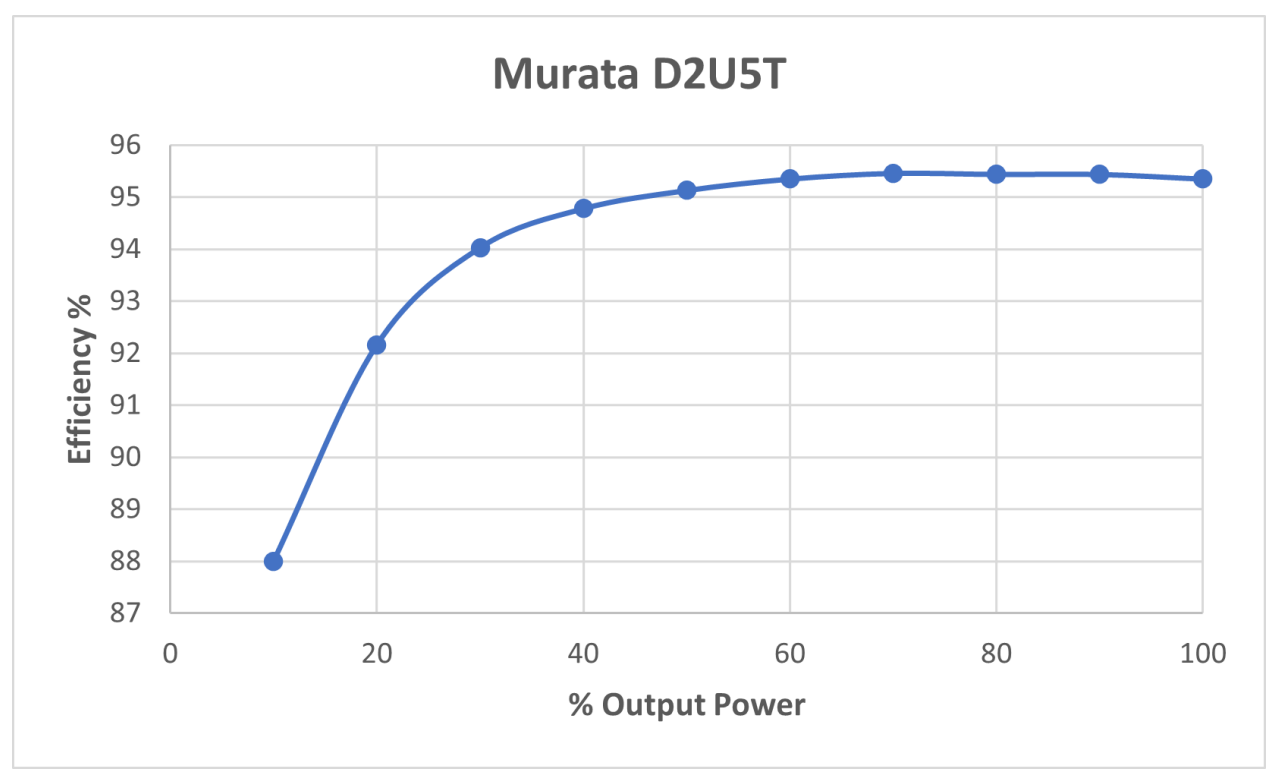

Figure A1. Efficiency curve for elevator rectifier [28].

\section{References}

1. Fairey, P.; Goldstein, P. Metrics for energy efficient buildings: How do we measure efficiency. In ACEEE Summer Study on Energy Efficiency in Buildings; ACEEE: Pacific Grove, CA, USA, 2016.

2. Alhorr, Y.; Eliskandarani, E.; Elsarrag, E. Approaches to reducing carbon dioxide emissions in the built environment: Low carbon cities. Int. J. Sustain. Built Environ. 2014, 3, 167-178. [CrossRef]

3. Lantero, A. The War of the Currents: AC vs. DC Power; Energy.Gov: Washington, DC, USA, 2013.

4. Dastgeer, F.; Kalam, A. Efficiency comparison of DC and AC distribution systems for distributed generation. In Proceedings of the 2009 Australasian Universities Power Engineering Conference, Adelaide, Australia, 27-30 September 2009; pp. 1-5.

5. Prabhala, V.A.; Baddipadiga, B.P.; Fajri, P.; Ferdowsi, M. An overview of direct current distribution system architectures \& benefits. Energies 2018, 11, 2463.

6. Sirsi, R.; Ambekar, Y. Efficiency of DC microgrid on DC distribution system. In Proceedings of the 2015 IEEE Innovative Smart Grid Technologies-Asia (ISGT ASIA), Bangkok, Thailand, 3-6 November 2015; pp. 1-6.

7. Vossos, V.; Gerber, D.; Bennani, Y.; Brown, R.; Marnay, C. Techno-economic analysis of DC power distribution in commercial buildings. Appl. Energy 2018, 230, 663-678. [CrossRef]

8. Vossos, E.; Gaillet-Tournier, M.; Gerber, D.; Nordman, B.; Brown, R.; Bernal, W.; Ghatpande, O.; Saha, A.; Deru, M.; Frank, S. Direct-DC Power in Buildings: Identifying the Best Applications Today for Tomorrow's Building Sector; Technical Report; Lawrence Berkeley National Lab. (LBNL): Berkeley, CA, USA, 2021.

9. Becker, D.J.; Sonnenberg, B. DC microgrids in buildings and data centers. In Proceedings of the 2011 IEEE 33rd International Telecommunications Energy Conference (INTELEC), Amsterdam, The Netherlands, 9-13 October 2011; pp. 1-7.

10. Frank, S.M.; Rebennack, S. Optimal design of mixed AC-DC distribution systems for commercial buildings: A Nonconvex Generalized Benders Decomposition approach. Eur. J. Oper. Res. 2015, 242, 710-729. [CrossRef] 
11. Seo, G.S.; Baek, J.; Choi, K.; Bae, H.; Cho, B. Modeling and analysis of DC distribution systems. In Proceedings of the 8th International Conference on Power Electronics-ECCE Asia, Jeju, Korea, 30 May-3 June 2011; pp. 223-227.

12. Kakigano, H.; Nomura, M.; Ise, T. Loss evaluation of DC distribution for residential houses compared with AC system. In Proceedings of the 2010 International Power Electronics Conference-ECCE ASIA, Sapporo, Japan, 21-24 June 2010; pp. 480-486.

13. Nilsson, D.; Sannino, A. Efficiency analysis of low-and medium-voltage DC distribution systems. In Proceedings of the IEEE Power Engineering Society General Meeting, Denver, CO, USA, 6-10 June 2004; pp. 2315-2321.

14. Salomonsson, D.; Sannino, A. Low-voltage DC distribution system for commercial power systems with sensitive electronic loads. IEEE Trans. Power Deliv. 2007, 22, 1620-1627. [CrossRef]

15. Gerber, D.L.; Vossos, V.; Feng, W.; Marnay, C.; Nordman, B.; Brown, R. A simulation-based efficiency comparison of AC and DC power distribution networks in commercial buildings. Appl. Energy 2018, 210, 1167-1187. [CrossRef]

16. Dastgeer, F.; Gelani, H.E. A Comparative analysis of system efficiency for AC and DC residential power distribution paradigms. Energy Build. 2017, 138, 648-654. [CrossRef]

17. Starke, M.; Tolbert, L.M.; Ozpineci, B. AC vs. DC distribution: A loss comparison. In Proceedings of the 2008 IEEE/PES Transmission and Distribution Conference and Exposition, Chicago, IL, USA, 21-24 April 2008; pp. 1-7.

18. Barros, J.; de Apráiz, M.; Diego, R.I. Power quality in DC distribution networks. Energies 2019, 12, 848. [CrossRef]

19. Van den Broeck, G.; Stuyts, J.; Driesen, J. A critical review of power quality standards and definitions applied to DC microgrids. Appl. Energy 2018, 229, 281-288. [CrossRef]

20. Whaite, S.; Grainger, B.; Kwasinski, A. Power quality in DC power distribution systems and microgrids. Energies 2015, 8, 4378-4399. [CrossRef]

21. Zhang, L.; Good, N.; Mancarella, P. Building-to-grid flexibility: Modelling and assessment metrics for residential demand response from heat pump aggregations. Appl. Energy 2019, 233, 709-723. [CrossRef]

22. Hutchinson, S.; Heredia, W.G.B.; Ghatpande, O.A. Resilience Metrics for Building-Level Electrical Distribution Systems with Energy Storage. 2021, Under Review.

23. Panteli, M.; Mancarella, P.; Trakas, D.N.; Kyriakides, E.; Hatziargyriou, N.D. Metrics and quantification of operational and infrastructure resilience in power systems. IEEE Trans. Power Syst. 2017, 32, 4732-4742. [CrossRef]

24. Turner, A.J.; Monahan, W.; Cotter, M. Quantifying the ilities: A literature review of robustness, interoperability, and agility. In Disciplinary Convergence in Systems Engineering Research; Springer: Cham, Switzerland, 2018; pp. 1035-1049.

25. Koç, Y.; Warnier, M.; Kooij, R.E.; Brazier, F.M. An entropy-based metric to quantify the robustness of power grids against cascading failures. Saf. Sci. 2013, 59, 126-134. [CrossRef]

26. Waters, C.E.; Polese, L.G.; Alahmad, M.; Frank, S.; Lee, K. Electrical distribution systems for commercial reference building models. J. Archit. Eng. 2014, 20, 04013005. [CrossRef]

27. Wang, N.; Gorrissen, W.J. Commercial Building Energy Asset Score System: Program Overview and Technical Protocol (Version 1.0); Technical Report; Pacific Northwest National Lab. (PNNL): Richland, WA, USA, 2013.

28. California Energy Commission, Grid Support Inverter List Full Data ADA. Available online: https://www.energy.ca.gov / media/2365 (accessed on 24 December 2021).

29. Crawley, D.B.; Pedersen, C.O.; Lawrie, L.K.; Winkelmann, F.C. EnergyPlus: Energy Simulation Program. ASHRAE J. 2000, 42, 49-56.

30. Dobos, A.P. PVWatts Version 5 Manual; National Renewable Energy Lab. (NREL): Golden, CO, USA, 2014. [CrossRef] 